\title{
DAMPAK BUDAYA PACU JAWI TERHADAP SOSIAL EKONOMI MASYARAKAT DI NAGARI TABEK KECAMATAN PARIANGAN KABUPATEN TANAH DATAR
}

\author{
Muhammad Trio Fajri ${ }^{1}$, Yurni Suasti, Ratna Wilis ${ }^{2}$ \\ Program Studi Pendidikan Geografi \\ Fakultas Ilmu sosial Universitas Negeri Padang \\ e-mail: muhammadtriofajri@yahoo.co.id
}

\begin{abstract}
ABSTRAK
Penelitian ini bertujuan untuk mengetahui dampak budaya Pacu Jawi terhadap sosial ekonomi masyarakat di Nagari Tabek Kecamatan Pariangan Kabupaten Tanah Datar. Jenis penelitian adalah penelitian kualitatif. Subjek penelitian yaitu kabid olahraga Dispapora Tanah Datar, ketua PORWI, ketua panitia Pacu Jawi, tokoh masyarakat 4 orang, pedagang 10 orang, joki 4 orang, wisatawan 9 orang dan masyarakat sekitar lokasi Pacu Jawi 9 orang. Teknik pengumpulan data melalui observasi, wawancara dan dokumentasi. Data dianalisis menggunakan reduksi data, penyajian data dan penarikan kesimpulan. Hasil penelitian menemukan bahwa pada saat Event Pacu Jawi secara ekonomi akan memberikan peluang timbulnya kegiatan ekonomi berupa kegiatan perdagangan dan parkir. Event ini mampu meningkatkan pendapatan pedagang berkisar antara Rp.300.000 sampai Rp.6.000.000. Sedangkan untuk parkir diperoleh pendapatan sekitar Rp.300.000 sekali event (3-5 kali). Selain itu, Pacu Jawi juga dapat meningkatkan nilai jual sapi yang digunakan untuk Pacu Jawi sampai tiga kali lipat dari harga semula. Event Pacu jawi juga dimanfaatkan oleh media massa untuk berita acara di TV mereka. Dari segi sosial, dapat menjaga nilai gotong royong dalam masyarakat seperti bergotong royong dalam menyiapkan dan membersihkan arena Pacu Jawi. Kemudian event ini juga dapat meningkatkan hubungan silaturrahmi antar masyarakat satu nagari dengan nagari lainnya. Event Pacu Jawi juga sebagai ajang sosialisasi memperkenalkan budaya lokal kepada wisatawan. Menarik minat wisatawan dan sebagai sarana hiburan bagi masyarakat
\end{abstract}

Kata Kunci : Dampak, Budaya Pacu Jawi, Sosial Ekonomi

\begin{abstract}
The research was aims to determine the culture impact of Pacu Jawi on socio-economic community in Tabek Pariangan District of Tanah Datar. The research method was qualitative method. The subjects of this research are head sport Dispapora district of Tanah Datar, head of PORWI, community leaders, committee, traders, jockeys, tourists, local people. Data collection techniques through observation, interview and documentation. Data analysis use data reduction, data presentation and conclusion. The results of the research found that at the time of Pacu Jawi event will provide economic opportunities for economic activities in the form of trade and parking activities. Event Pacu Jawi is able to increase the income of traders ranging from Rp.300.000 to Rp. 6,000,000. whereas for the parking obtained revenues of about Rp.300.000 in one event (within 3-5 times). Besides Pacu Jawi culture can also increase the sale value of cows used for Pacu Jawi up to three times the original price. Event Pacu Jawi is also used by the mass media for news events on their TV. From a social point of view, it can maintain the value of mutual cooperation in society such as mutual cooperation in preparing arena Pacu Jawi and clean up arena Pacu Jawi post Pacu Jawi. then this ivent can also improve the relationship between the community silaturrahmi one nagari with other nagari relationship between fellow Pacu Jawi jockeys, as a socialization event to introduce local culture both to the public and tourists and as a means of entertainment for the community
\end{abstract}

Keywords: Impact, Pacu Jawi Culture, Socio-Economic

\footnotetext{
${ }^{1}$ Mahasiswa Program Studi Pendidikan Geografi Universitas Negeri Padang.

${ }^{2}$ Dosen Jurusan Geografi Fakultas Ilmu Sosial Universitas Negeri Padang, pembimbing I Dra. Yurni Suasti, M.Si, pembimbing II Ratna Wilis, S.Pd, M.P.
} 


\section{PENDAHULUAN}

Negara Indonesia merupakan negara kepulauan yang terdiri dari 17.000 pulau baik besar maupun kecil, Dengan wilayah yang luas ini Indonesia banyak memiliki objek wisata yang diminati oleh wisatawan, seperti Pantai Gondoriah di Pariaman, Pulau Pasumpahan di Pesisir Selatan dan masih banyak lagi yang lainnya. Selain itu Indonesia juga kaya akan budaya dan adat istiadatnya yang unik.

Keunikan yang demikian itu, banyak wisatawan yang datang dan menyaksikan berbagai macam tradisi dan kebudayaan tersebut sehingga akan meningkatkan perekonomian di sektor pariwisatanya.

Sumatera Barat merupakan salah satu Provinsi yang menjadi daerah tujuan destinasi wisata di Indonesia. Salah satu objek wisata yang sering di kunjungi oleh wisatawan di Sumatera Barat yaitu Istano Basa Pagaruyung yang berada di Kabupaten Tanah Datar.

Selain Istano Basa Pagaruyung, Kabupaten Tanah Datar juga memiliki banyak daya tarik wisata lainnya seperti: Danau Singkarak, Air Terjun Lembah Anai, Air Terjun Mayang Taurai, Batu Batikam, Nagari Tuo Pariangan, Pemandian Air Panas, Ngalau Pangian dan masih banyak lagi yang lainnya. Kabupaten Tanah Datar juga kaya dengan keseniannya tradisionalnya seperti talempong pacik, saluang, rabab, randai, serta tari-tarian dan banyak tradisi lainnya.

Tradisi Pacu Jawi yakni sebuah tradisi unik dan menarik yang sudah ada sejak ratusan tahun lalu yang dilaksanakan setelah panen padi dilakukan di Kabupaten Tanah Datar. Pacu berarti lomba kecepatan dan Jawi maksudnya sapi atau lembu.

Pacu Jawi dilaksanakan pada sawah yang berlumpur dan berair dan setiap perlombaan hanya dilepas satu pasang satu pasang yang mana kedua sapi dipasangkan alat bajak yang terbuat dari kayu dan diikat agar kedua sapinya tidak pisah, sapi tersebut dikendarai oleh seorang yang disebut dengan joki dengan berdiri di ujung kerangka bajak dari kedua sapi tersebut sambil memegang ekor kedua sapi. Semakin kuat joki menggigit ekor sapi semakin cepat pula sapi itu akan berlari.

Dari 14 kecamatan di Kabupaten Tanah Datar, penyelenggaraan acara Pacu Jawi hanya dilakukan di empat Kecamatan dengan periode yang tidak menetap yakni di Kecamatan Rambatan, Pariangan. Sungai Tarab. dan Lima Kaum.

Secara geografis keempat kecamatan ini berada berdekatan yang memiliki luas sawah $35,12 \mathrm{~km}^{2}$, jumlah sapi 2987 ekor, luas pemukiman 12.13 km2 (BPS, 2016). Luas sawah jauh melebihi luas pemukiman penduduk dan jumlah sapi yang cukup banyak, karena lokasi dan periode yang tidak menetap dalam melakukan acara Pacu Jawi ini maka peneliti memfokuskan penelitian di Nagari Tabek Kecamatan Pariangan Kabupaten Tanah Datar.

Tradisi Pacu Jawi diselengarakan dengan acara adat dan kesenian lainnya seperti pidato adat, tari-tarian sebagai sarana hiburan. Pemenang dari lomba Pacu Jawi ini akan ditentukan dengan cara melihat sapi siapa yang mampu 
berlari paling lurus ke depan, tidak melenceng dan terpisah atau bahkan keluar dari arena pacuan yang telah ditentukan. Filosofi yang terdapat dari Pacu Jawi ini yaitu Sapi saja bisa berjalan lurus apalagi manusia yang memiliki akal dan pikiran tentu tinggi nilainya dan akan lebih dihargai.

Filosofi yang terdapat dari Pacu Jawi ini yaitu sapi saja bisa berjalan lurus apalagi manusia yang memiliki akal dan pikiran tentu tinggi nilainya dan akan lebih dihargai. Selain itu filosofi lain seperti pemimpin dan rakyat yang digambarkan bisa berjalan bersama. Oleh karena itu sapi yang dipakai untuk Pacu Jawi ada 2 ekor.

Banyak dampak positif yang timbulkan dari Pacu Jawi ini seperti menerapkan nilai-nilai gotong royong yang bisa diterapkan masyarakat baik sebelum maupun sesudah diadakannya acara Pacu Jawi seperti gotong royong mempersiapkan arena untuk Pacu Jawi. selain itu pendapatan masyarakat juga akan bertambah ketika Pacu Jawi ini dengan memanfaatkannya untuk berdagang pada acara Pacu Jawi.

Untuk mendapatkan gambaran yang pasti mengenai dampak yang ditimbulkan dari budaya Pacu Jawi peneliti tertarik untuk melakukan penelitian dengan mengambil judul dampak budaya Pacu Jawi terhadap sosial ekonomi masyarakat di Nagari Tabek Kecamatan Pariangan Kabupaten Tanah Datar".

Masyarakat merupakan sekumpulan manusia yang relatif mandiri, hidup bersama cukup lama, mendiami wilayah tertentu, memiliki kebudayaan sama dan melakukan sebagian besar kegiatan dalam kelompok tersebut, Horton (dalam Setiadi, 2011: 36). Masyarakat merupakan setiap kelompok manusia yang hidup dan bekerjabersama cukup lama sehingga mereka dpat mengatur diri mereka dan menganggap diri mereka sebagai suatu kesatuan sosial dengan batas- batas yang dirumuskan dengan jelas. Linton (dalam Soekanto, 2012: 22).

Dampak secara sederhana dapat diartikan sebagai pengaruh atau akibat dari keputusan atau kegiatan yang dilakukan oleh seseorang maupun sekelompok orang baik itu dampak positif maupun dampak negatif. Dampak positif sendiri yaitu akibat atau pengaruh yang mengentungkan dari berbagai peristiwa-peristiwa yang terjadi.

Menurut Fardani (dalam Handayani, 2013:21) dampak merupakan suatu yang muncul setelah adanya suatu kejadian. pengaruh yang di maksud adalah akibat yang terjadi pada masyarakat baik karena suatu kejadian itu maupun hal lainnya mempengaruhi masyarakat.

Dari uraian diatas dapat disimpulkan bahwa dampak merupakan pengaruh sesuatu yang menimbulkan akibat, dari setiap keputusan yang diambil oleh seorang maupun kejadiankejadian baik itu berdampak positif maupun dampak negatif. Dalam konteks penelitian ini adalah dampak positif dari tradisi Pacu Jawi terhadap sosial ekonomi masyarakat.

Kata kebudayaan berasal dari kata Sansekerta, budhayah yaitu bentuk jamak dari kata buddhi yang berarti 
budi atau akal. Jadi kebudayaan itu dapat diartikan "hal-hal yang bersangkutan dengan akal”. Tylor (dalam Soekanto 2012:150) kebudayaan adalah kompleks yang mencakup pengetahuan, kepercayaan, kesenian, moral, hukum, adat istiadat dan lain kemampuan-kemampuan serta kebiasaan-kebiasaan yang di dapat oleh manusia sebagai anggota masyarakat.

Selo Soemardjan dan Soelaeman Soemardi (dalam Soekanto, 2012:151) Kebudayaan sebagai hasil karya, rasa, cipta masyarakat. Karya masyarakat menghasilkan teknologi dan kebudayaan jasmaniah yang diperlukan oleh manusia untuk mengolah alam agar dapat di gunakan oleh masyarakat. Rasa yang meliputi jiwa manusia dalam nilainilai sosialnya termasuk agam, ideologi, kesenian. Dengan kata lain yaitu keseluruhan yang mencakup hasil ekspresi dari manusia itu sendiri.

Kroeber (dalam Gunawan 1999:68) kebudayaan merupakan keseluruhan reaksi gerak, kebiasaan, tata cara, gagasan dan nilai-nilai yang di pelajari dan di wariskan serta prilaku yang di timbulkannya.

Berdasarkan uraian diatas dapat disimpulkan bahwa kebudayaan adalah suatu hasil karya cipta manusia berupa ide-ide gagasan yang didapat dan diwariskan oleh anggota masyarakat ada yang berbentuk aturan-aturan, petunjuk serta kebiasaan, dan mereka menjunjung tinggi semuanya tersebut dan bersifat abstrak.

Kegiatan Pacu Jawi merupakan acara permainan tradisional anak nagari (desa) yang telah ada sejak ratusan tahun yang lalu dan berkembang di
Kabupaten Tanah Datar Propinsi Sumatera Barat. Pacu berarti lomba kecepatan dan Jawi maksudnya Sapi atau Lembu. Di Sumatera Barat sapi biasa disebut dengan Jawi. Kegiatan ini hanya ada di Kabupaten Tanah Datar dan sedikit di Kabupaten 50 Kota. Di Kabupaten Tanah Datar-pun hanya pada empat kecamatan, yaitu Kecamatan Pariangan, Kecamatan Rambatan, Kecamatan Lima Kaum dan Kecamatan Sungai Tarab.

Pacu Jawi dilaksanakan secara bergiliran pada empat kecamatan, yang di laksanakan pada setiap hari Sabtu dan berlangsung selama 4 minggu berturut turut dan telah menjadi sarana hiburan yang ditunggu-tunggu oleh masyarakat setempat serta telah ada sejak ratusan tahun yang lalu. Pada kegiatan ini juga dipadukan dengan tradisi masyarakat berupa arak-arakan (pawai) pembawa dulang/jamba yang berisi makanan dan arak-arakan sapi terbaik yang didandani dengan aksesoris berupa suntiang serta pakaian. Biasanya acara tradisi ini diselenggarakan pada minggu ke-IV atau pada waktu penutupan acara Pacu Jawi dan menjadi perhelatan yang besar di daerah itu. serta berbagai permainan seni budaya tradisional seperti taritarian pencak silat, tari piring serta kesenian yang lainnya.

Pacu Jawi dilakukan setelah selesai masa panen dilaksanakan, di sawah milik masyarakat dengan syaratsyarat sebagai berikut :

1. Sawah panjang dan lebar

2. Sawah tidak dalam

3. Sawah yang disekitar lokasi harus selesai panen agar sapi- 
sapi tidak merusak sawah disekitarnya.

4. Pematang sawah lebar untuk para penonton menyaksikan Pacu Jawi

5. Di sekitar lokasi sawah pacuan terdapat lokasi peristirahatan sapi sebelum masuk ke arena pacuan.

6. Terdapat lokasi untuk lokasi permainan anak nagari 'desa' berupa musik tradisional dan tari-tarian, tempat kuliner, dan tempat upacara menunggu tamu dan upacara pembukaan, biasa disebut dengan balai-balai.

Ketika kegiatan ini diadakan pada satu kecamatan maka pesertanya tidak hanya dari kecamatan yang bersangkutan saja akan tetapi dari Kecamatan lain juga akan berdatangan. Dalam satu hari perlombaan, jumlah sapi yang berpacu mencapai 120 ekor.

Pacu Jawi di lombakan secara berpasangan yang dikendalikan oleh seorang anak joki yang berdiri di ujung tangkai bajak yang telah di pasangkan pada sapinya dan berpegangan pada ke dua ekor sapi serta sesekali menggigit ekor sapinya, semakin kuat joki menggigit ekor sapinya maka larinya juga semakin kencang pula, uniknya Pacu Jawi ini tidak di lombakan dengan pasangan lawan akan tetapi hanya di lepas satu pasang di setiap lombanya agar tidak ada unsur judi di dalamnya.

Cara untuk menetukan pemenangnya unik pula yaitu dengan cara melihat pasangan sapi mana yang mampu menuntun temannya berlari lurus ke depan dan tidak melenceng ke kiri kanan atau bahkan keluar dari arena pacuan. Filosofi yang terkandung di dalamnya yaitu sapi saja bisa berjalan lurus apalagi manusia yang memiliki akal dan pikiran tentu tinggi nilainya dan akan lebih dihargai serta pemimpin dan rakyat yang digambarkan bisa berjalan bersama. Oleh karena itu sapi yang dipakai untuk Pacu Jawi ada 2 ekor.

Acara dimulai sekitar jam sepuluh pagi sampai jam lima sore. Pada waktu perlombaan berlangsung kadangkala juga terjadi transaksi jual beli sapi oleh para pedagang dan pemilik sapi. Biasanya sapi yang telah sering memenangkan lomba akan naik harganya sehingga akan menjadi kebanggaan tersendiri bagi pemiliknya dan diincar oleh banyak orang.

\begin{tabular}{lcr}
\multicolumn{1}{c}{ Sosial } & dalam ilmu & sosial \\
menunjuk & pada objeknya & yaitu \\
masyarakat. & Sedangkan & dalam
\end{tabular} sosiologi, manusia juga disebut sebagai makhluk sosial yang artinya manusia tidak dapat hidup tampa adanya bantuan orang lain disekitarnya. Kata sosial juga marujuk kepada interaksi masyarakat baik itu interaksi dengan sesamanya maupun interaksi dengan lingkungannya.

Kata ekonomi berasal dari bahasa Yunani : Oikos dan Nomos. Oikos berarti rumah tangga sedangkan Nomos berarti aturan, kaidah atau pengelolaan. Jadi ekonomi dapat dapat diartikan sebagai kaidah-kaidah, aturan-aturan atau cara pengelolaan suatu rumah tangga. Ekonomi tidak terlepas dari produksi distribusi dan konsumsi.

Menurut Soekanto (dalam Usman 2011:7) Sosial ekonomi merupakan posisi seseorang dalam masyarakat 
berkaitan dengan orang lain dalam arti lingkungan, pergaulan, prestasi, hak-hak serta kewajiban dalam hubungannya dengan sumber daya.

Sosial ekonomi merupakan kedudukan atau posisi seeorang dalam kelompok manusia yang di tentukan oleh jenis aktivitas ekonomi, pendapatan, mata pencaharian, tingkat pendidikan, jenis rumah tinggal dan jabatan dalam organisasi Abdulsyani (dalam Usman 2011:7).

Ada beberapa faktor yang menjadi indikator sosial ekonomi yaitu kondisi kependudukan yang ada, tingkat pendidikan, tingkat pendapatan, tingkat kesahatan, tingkat konsumsi, perumahan dan lingkungan masyarakat. Kusnadi (dalam Hailinda 2011:7).

Berdasarkan beberapa pengertian diatas, maka dapat disimpulkan bahwa sosial ekonomi dalam penelitian ini adalah kedudukan seseorang dalam masyarakat untuk memenuhi kebutuhan hidupnya yang mencakup tingkat pendapatan, pekerjaan dan lingkungannya.

\section{METODE PENELITIAN}

Jenis penelitian ini adalah penelitian kualitatif. Penelitian ini di laksanakan di Nagari Tabek Kecamatan Pariangan Kabupaten Tanah Datar. Informan dalam penelitian ini terdiri dari kabid olahraga Dispapora Tanah Datar, Ketua PORWI Tanah Datar, tokoh masyarakat, panitia penyelenggara Pacu Jawi, pedagang, joki, wisatawan, serta masyarakat yang berada di sekitar lokasi Pacu Jawi.

Teknik pengumpulan data yang digunakan dalam penelitian ini adalah observasi, wawancara dan dokumentasi. Teknik analisis data yang digunakan adalah reduksi data, penyajian data dan penarikan kesimpulan. Kemudian data yang di dapat dari informan diolah secara deskriptif yang berbentuk katakata dan uraian. Teknik keabsahan datanya manggunakan triangulasi sumber dan triangulasi metode.

\section{HASIL DAN PEMBAHASAN}

\section{A. Gambaran Umum Daerah Penelitian}

Secara astronomis Kecamatan Pariangan terletak antara $100^{\circ} 28^{\prime} 00^{\prime \prime} \mathrm{BT}$ - 100 41'35'BT dan antara $0^{\circ} 23^{\prime} 35^{\prime \prime} \mathrm{LS}$ - 0³0'40"LS dengan luas wilayah 76,43 $\mathrm{Km}^{2}$. Secara umum Kecamatan Pariangan beriklim tropis dengan curah hujan $2061 \mathrm{~mm}^{3} /$ tahun. Wilayah Kecamatan Pariangan secara administratif dibagi kedalam 6 Nagari, yaitu: Batu basa, Tabek, Sawah Tangah, Simabur, Pariangan dan Sungai Jambu. Peta lokasi Pacu Jawi di sajikan pada gambar 1.

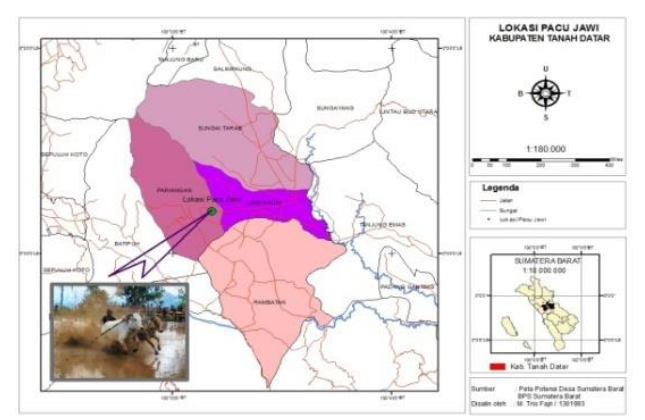

Gambar 1. Peta Lokasi Pacu Jawi

Secara administratif Kecamatan Paringan berbatasan dengan :

Sebelah utara :Kecamatan Sungai Tarab

Sebelah Selatan :Kecamatan Rambatan

Sebelah Barat :Kecamatan Batipuh

Sebelah Timur :Kecamatan Lima kaum 
Berdasarkan data yang diperoleh dari Badan Pusat Statistik Kabupaten Tanah Datar jumlah penduduk Kecamatan Pariangan tahun 2016 memiliki jumlah 19.613 jiwa dengan jumlah penduduk laki-laki 9560 jiwa dan penduduk perempuan 10.053 jiwa. Dengan luas wilayah sekitar 76,43 $\mathrm{Km}^{2}$, maka dapat diketahui bahwa kecamatan Pariangan memliki kepadatan penduduk yaitu $257 \mathrm{Jiwa} / \mathrm{Km}^{2}$.

\section{A. Sejarah dan pengelolaan Pacu jawi}

Berdasarkan data yang diperoleh dari beberapa informan diketahui bahwa Pacu Jawi sudah ada sejak zaman nenek moyang dahulu, Pacu Jawi pertama kali dilaksanakan di sawah Pancuang Talang di Jorong Pariangan Nagari Pariangan Kecamatan Pariangan kepunyaan Datuk Marajo Depang, dapat dikatakan bahwa Pacu Jawi ini berasal dari Nagari tuo Pariangan, sampai sekarang yang mengadakan Pacu Jawi hanya ada pada 4 Kecamatan di Tanah Datar yaitu Kecamatan Pariangan, Rambatan, Lima Kaum dan Sungai Tarab.

Sistem pengelolaannya sebelum Pacu Jawi dilaksanakan dimusyawarahkan terlebih dahulu bersama ketua PORWI, tokoh masyarakat, pemuda serta bundo kanduang. Pada musyawarah tersebut ditentukan sawah yang akan digunakan untuk pacu jawi serta dibentuk juga panitia pelaksananya.

Setelah itu masyarakat bergotong royong menyiapkan arena, serta tempat berdagang, Pacu Jawi dilaksanakan 3 sampai 5 kali dalam satu tempat, pelaksanaannya selalu dilakukan pada hari Sabtu saja sehingga akan memakan waktu sampai satu bulan.

Ketika acara pembukaan diadakanlah lomba pacu pita yang di ikuti oleh 3-5 pasang sapi pada garis start, dimana pada garis finish sudah terbentang tali atau pita, jadi siapa peserta yang duluan memutus pitanya dialah pemenangnya, kemudian baru dilaksanakan Pacu Jawi biasa yang mana di garis start hanya dilepas satu pasang satu pasang sapi setiap perlombaannya. Sistem penilaian yaitu dengan melihat sapi siapa yang mampu berlari lurus kedepan yang tidak melenceng kekiri atau kekanan dan tidak terpisah dengan pasangannya dialah pemenangnya. Pada acara penutupan dilaksanakan juga arak arakan sapi yang dihiasi pernak pernik serta pakaian atau biasa disebut dengan suntiang. Pacu Jawi dalam tahun 2017 ada 9 kali dilaksanakan dengan tempat yang selalu berpindah-pindah dari satu tempat ke tempat lainnya dalam 4 kecamatan. Sapi yang di pakai dalam acara Pacu Jawi adalah sapi kampung berjenis kelamin jantan, memiliki badan panjang, kulit tipis, berbulu kasar, telinga kecil dan memiliki pusar-pusar di keningnya serta mempunyai mata yang melotot dan tajam.

Perawatan sapi Pacu Jawi sama dengan sapi biasa, namun ketika hendak melakukan Pacu Jawi sebelum berangkat diberikan nutrisi khusus kepada sapinya seperti suplemen penambah stamina, telur ayam, serta madu lebah agar sapinya besemangat dan bertenaga ketika berlomba.

Peserta Pacu Jawi hanya dari empat Kecamatan saja yaitu Kecamatan 
Pariangan, Rambatan, Lima Kaum dan Sungai Tarab, terkadang ada juga yang datang dari Payakumbuh. Para peserta tidak ada yang membayar untuk ikut dalam pacu jawi kecuali peserta dari tuan rumah membayar iuran sebesar Rp.30.000. Pengunjung yang menyaksikan budaya Pacu Jawi juga beragam, mulai dari masyarakat sekitar sampai wisatawan manca, tidak hanya itu saja media cetak dan elektronik pun sudah banyak yang datang dan sering melakukan liputan tentang Pacu Jawi.

Pemasukan Pacu Jawi yaitu dari bantuan oleh pemerintah daerah, dari sumbangan perantau dan masyarakat, Selain itu ada juga dari para pemilik sapi tuan rumah, sumbangan pedagang, parkiran serta sponsor. Yang paling besar perannya dalam pemasukan dana yaitu dari turis-turis yang datang seperti fotografer dan stasiun TV karena mereka akan memberikan kontribusinya sumbangan. Kendala dalam Pacu Jawi ini seperti air, jika tidak ada air maka tidak mungkin dilaksanakan selanjutnya masalah masalah dana

A. Dampak budaya Pacu Jawi terhadap perekonomian masyarakat

Dari budaya Pacu Jawi banyak sekali dampak yang ditimbulkan menurut Abdulsyani (dalam Usman 2011:7) yang menjadi indikator sosial ekonomi yaitu pendapatan, mata pencaharian, tingkat pendidikan, jenis rumah tinggal dan jabatan dalam organisasi. Dengan diadakannya event Pacu Jawi akan memberikan peluang kepada masyarakat sekitar untuk kegiatan ekonomi seperti berdagang dan parkir seperti banyaknya muncul para pedagang-pedagang dadakan yang menjajakan dagangannya ketika event Pacu Jawi seperti pedagang minuman, nasi, ketupat dan gorengan. Jumlah pendapatan pedagang ketika Pacu Jawi disajikan pada tabel 1

Tabel 1. Jumlah Pendapatan Pedagang Ketika Pacu Jawi

\begin{tabular}{|c|l|c|c|}
\hline No & \multicolumn{1}{|c|}{ Nama } & $\begin{array}{c}\text { Pekerjaan ketika ada Pacu } \\
\text { Jawi }\end{array}$ & $\begin{array}{c}\text { Pendapatan ketika acara } \\
\text { Pacu Jawi (Rp) }\end{array}$ \\
\hline 1. & Migeslakespi & Pedagang & 300.000 \\
\hline 2. & Yondrianto & Pedagang & 800.000 \\
\hline 3. & Asep & Pedagang & 300.000 \\
\hline 4. & Sherly Eka Puspita & Pedagang & 850.000 \\
\hline 5. & Putri anjela & Pedagang & 450.000 \\
\hline 6. & Widia & Pedagang & 300.000 \\
\hline 7. & Ulfa Deli Sambra & Pedagang & 300.000 \\
\hline 8. & Ritnawati & Pedagang & 800.000 \\
\hline 9. & Fatmawati & Pedagang & 400.000 \\
\hline 10. & Nasrul & Pedagang & 200.000 \\
\hline 11 & Hena & Pedagang & 1.500 .000 \\
\hline 12 & Fatmawati & Pedagang & 800.000 \\
\hline 13 & Wirna Misdarti & Pedagang & 400.000 \\
\hline 14 & Mudasir & Pedagang & 150.000 \\
\hline
\end{tabular}


Dari tabel 1 dapat dilihat pendapatan yang diterima masyarakat ketika sekali acara berkisar antara 50,000 Rupiah sampai 1.000 .000 Rupiah. Dalam satu kali acara, acara pacu jawi diselenggarakan 3 sampai 5 kali dalam satu bulan artinya pendapatan masyarakat berkisar antara 300.000 sampai 6.000.000 Rupiah sebulan. Selain itu dari budaya Pacu jawi sapi para peternak sapi akan meningkat harga jualnya bahkan sampai dua kali lipat naik harganya, yang biasanya harga sapi Rp.12.000.000 satu ekor bisa menjadi RP.30.000.000.

Masyarakat yang berada di sekitar lokasi bisa membuka lahan parkiran seperti memanfaatkan pekarangan di depan rumahnya untuk parkiran sehingga akan menambah penghasilan juga bagi mereka, selain itu dengan acara Pacu Jawi akan menarik minat wisatawan baik yang lokal maupun manca negara datang ke Sumatera Barat untuk menyaksikan acara Pacu Jawi dan tidak menutup kemungkinan para wisatawan ini akan juga berkunjung ke tempat wisata yang lainnya seperti Nagari Tuo Pariangan, Istano basa Pagaruyung dan yang tak kalah penting setiap wisatawan ini akan memberikan kontribusi atau sumbangan untuk Pacu Jawi. Pacu Jawi juga dimanfaatkan oleh media massa untuk berita acara $\mathrm{Tv}$ mereka.

\section{B. Dampak Budaya Pacu Jawi} terhadap Sosial Masyarakat

Dari segi sosial dapat menjaga nilai gotong royong dalam masyarakat seperti bergotong royong dalam menyiapkan arena Pacu Jawi seperti mengakirkan air untuk sawah yang akan di jadikan arena, membuat pagar pembatas agar sapi-sapi yang berlomba tidak keluar dari lintasan, ketika acara sudah selesai masyarakat juga akan bergotong royong lagi membersihkan arena lomba.

Pacu Jawi juga sebagai sarana hiburan bagi masyarakat mulai dari anak-anak sampai yang tua karena Pacu Jawi unik beda dari yang lain karena arenanya di sawah yang berlumpur dan berair, kemudian event ini juga dapat meningkatkan hubungan silaturrahmi antar masyarakat satu nagari dengan nagari lainnya seperti hubungan antara sesama para joki Pacu Jawi. selain itu budaya pacu jawi juga di jadikan sebagai ajang sosialisasi memperkenalkan budaya lokal khususnya Pacu Jawi baik kepada masyarakat maupun wisatawan.

Dengan adanya event Pacu Jawi ini akan menambah semangat peternak sapi untuk beternak sapi karena sapi yang mereka pelihara akan naik harganya. Selain itu dengan banyaknya wisatawan asing yang datang menyaksikan Pacu Jawi masyarakat akan lebih tertarik dan termotivasi untuk pandai berbahasa inggris setidaknya berkomunikasi menjelaskan apa itu Pacu Jawi kepada wisatawan asing sehingga mereka mengerti dan paham dan tidak hanya sekedar menonton saja.

PENUTUP

\section{A. Kesimpulan}

Berdasarkan hasil penelitian dapat disimpulkan bahwa Pacu Jawi sudah ada sejak zaman dahulu, Pacu Jawi pertama kali dilaksanakan di sawah Pancuang Talang di Nagari 
Pariangan kepunyaan Datuk Marajo Depang, yang mengadakan Pacu Jawi hanya ada pada 4 Kecamatan di Tanah Datar yakni Kecamatan Pariangan, Rambatan, Lima Kaum dan Sungai Tarab. Pada tahun 2017 ada 9 kali diadakan Pacu Jawi dengan waktu yang tidak menentu dengan periode yang tidak menetap dan selalu berpindah pindah tergantung ketersediaan air di lokasi karena lokasinya harus berair dan berlumpur.

event Pacu Jawi secara ekonomi akan memberikan peluang kepada masyarakat sekitar untuk kegiatan ekonomi seperti berdagang dan parkir. event Pacu Jawi ini mampu meningkatkan pendapatan pedagang yang berkisar Rp.300.000 Rupiah sampai Rp. 6.000.000 Rupiah dalam sekali ivent (dalam jangka waktu 3-5 hari). Sedangkan untuk parkir diperoleh pendapatan sekitar Rp.300.000 Rupiah dalam sekali event. Selain itu budaya Pacu Jawi juga dapat meningkatkan nilai jual sapi yang digunakan untuk event Pacu Jawi. Nilai jual tersebut bisa dua kali lipat sampai tiga kali lipat dari harga semula. Pacu Jawi juga dimanfaatkan oleh media seperti stasiun TV yang meliput acara Pacu Jawi sebagai berita acara TV mereka.

Dari segi sosial dapat menjaga nilai gotong royong dalam masyarakat seperti bergotong royong dalam menyiapkan arena Pacu Jawi. mempererat hubungan silaturrahmi antar masyarakat seperti hubungan antara sesama joki Pacu Jawi, ajang sosialisasi memperkenalkan budaya lokal kepada masyarakat maupun wisatawan, menarik minat wisatawan karena Pacu Jawi ini unik karena dilaksanakan di sawah yang berlumpur dan berair.

\section{B. Saran}

1. Diharapkan sistem pengelolaan ditingkatkan dikelola dengan sebaik-baiknya seperti membuat karcis masuk untuk penonton, uang masuk untuk ikut serta bagi para joki serta pemilik sapi

2. Tingkat keamanannya supaya lebih di tingkatkan seperti pagar pembatas

3. Informasi promosi seperti iklan baliho lebih di tingkatkan seperti memmbuat baliho di pusat keramaian

4. Sebaiknya para pedagang yang berjualan di lokasi lebih tata rapi

5. Diharapkan agar dibuatnya tempat solat di lokasi Pacu Jawi solat

6. Bagi para peneliti, penelitian ini bisa menjadi bahan rujukan untuk penelitian selanjutnya.

\section{DAFTAR PUSTAKA}

BPS Kabupaten Tanah Datar. 2017. Kecamatan Pariangan Dalam Angka.

https://tanahdatarkab.bps.go.id/ publication/2017/09/23/cfa9be4 29c59fcc5835294c2/kecamatanpariangan-dalam-angka2017.html. (diakses tanggal 3 Desember 2017)

Gunawan, Samuel. 1999. Antropologi Budaya. Jakarta: Erlangga

Hailinda. 2011. Kondisi Sosial Ekonomi Masyarakat Pasca Pembangunan jalan Lintas Bono di Kecamatan Bunut Kabupaten 
Palalawan. Skripsi. Jurusan Geografi FIS. Universitas Negeri Padang.

handayani, eka. 2013. Dampak Pengembangan Wilayah Perumahan Terhadap Perubahan Sosial Ekonomi Penduduk Asli Kelurahan Koto Tangah Kecamatan Payakumbuh Barat Kota Payakumbuh. Skripsi. Jurusan Geografi FIS. Universitas Negeri Padang.

Setiadi, Elly M dan Usman Kolip. 2011. Pengantar Sosiologi. Jakarta: Kencana Pranadamedia Group

Soekanto, Soerjono. 2012. Sosiologi Suatu Pengantar. Jakarta: PT Raja Grafindo Persada

Usman. 2011. Kondisi Sosial Ekonomi Masyarakat Peserta Program Nagari Prioritas di Kanagarian Parit Kecamatan Koto Balingka Kabupaten Pasaman Barat. Skripsi. Jurusan Geografi FIS. Universitas Negeri Padang. 